\title{
Article
}

\section{Molecular Packing and Arrangement Govern the Photo- Oxidative Stability of Organic Photovoltaic Materials}

William R. Mateker, Thomas Heumueller, Rongrong Cheacharoen, I. T. Sachs-Quintana, Julien Warnan, Xiaofeng Liu, Guillermo C. Bazan, Pierre M. Beaujuge, and Michael D. McGehee

Chem. Mater., Just Accepted Manuscript • DOI: 10.1021/acs.chemmater.5b02341 • Publication Date (Web): 19 Aug 2015

Downloaded from http://pubs.acs.org on August 25, 2015

\section{Just Accepted}

"Just Accepted" manuscripts have been peer-reviewed and accepted for publication. They are posted online prior to technical editing, formatting for publication and author proofing. The American Chemical Society provides "Just Accepted" as a free service to the research community to expedite the dissemination of scientific material as soon as possible after acceptance. "Just Accepted" manuscripts appear in full in PDF format accompanied by an HTML abstract. "Just Accepted" manuscripts have been fully peer reviewed, but should not be considered the official version of record. They are accessible to all readers and citable by the Digital Object Identifier (DOI®). "Just Accepted" is an optional service offered to authors. Therefore, the "Just Accepted" Web site may not include all articles that will be published in the journal. After a manuscript is technically edited and formatted, it will be removed from the "Just Accepted" Web site and published as an ASAP article. Note that technical editing may introduce minor changes to the manuscript text and/or graphics which could affect content, and all legal disclaimers and ethical guidelines that apply to the journal pertain. ACS cannot be held responsible for errors or consequences arising from the use of information contained in these "Just Accepted" manuscripts. 


\section{Introduction}

Research effort directed to improving the power conversion efficiency of organic solar cells (OSCs) has driven it towards and above $10 \% .{ }^{1-7}$ With such a promising initial efficiency, the long-term performance of OSCs also needs to be considered. ${ }^{8,9}$ Extrapolated lifetimes of 2-3 years are reported in glass-on-glass encapsulated OSCs using the polymer poly(3-hexylthiophene-2,5-diyl) (P3HT) blended with [6,6]-phenyl- $\mathrm{C}_{60}$-butyric acid methyl ester (PCBM), ${ }^{10}$ and lifetimes of 7-10 years are reported in encapsulated OSCs with the polymer poly[9'-heptadecanyl-2,7-carbazole-alt-5,5-(4',7'-di-2-thienyl-2', 1',3'benzothiadiazole) (PCDTBT) $)^{11}$ and fullerene $[6,6]-$ phenyl- $\mathrm{C}_{70}$-butyric acid methyl ester $\left(\mathrm{PC}_{71} \mathrm{BM}\right){ }^{12,13}$ When polymer solar cells made from PCDTBT and $\mathrm{PC}_{71} \mathrm{BM}$ are illuminated in an environment with less than 0.1 parts per million (ppm) oxygen and water, extrapolated lifetimes approaching 20 years are observed, ${ }^{14}$ which rivals the lifetimes observed in some evaporated small-molecule solar cells. ${ }^{15}$ While such observations are promising, a more fundamental understanding of photo-degradation processes that lead to short-term burn-in ${ }^{16,17}$ and long-term performance loss is still needed. In either case, the most photochemically robust materials that perform well in OSCs are sought.

Design rules for developing photochemically robust OSC materials are only beginning to emerge. One inherent difficulty with assessing OSC material stability is the experimental length. In an effort to accelerate material ageing, researchers illuminate thin films of OSC materials in air. ${ }^{18}$ The degradation of the OSC material is measured by tracking a decrease in the film absorption over time, which usually occurs on the span of hours. The loss of absorption is attributed to a loss of extended $\pi$-conjugation in the OSC material through photochemical reactions with oxygen, which generally occur through a free-radical mechanism. ${ }^{19-23}$ This procedure, termed photobleaching, gives researchers a quick screen of a material's photochemical stability, and can at least be used for comparison between materials. Photobleaching is particularly relevant for OSCs in low-cost packaging. 
Another challenge to establishing general design principles is the chemical variety of OSC materials. ${ }^{24}$ Many of the high efficiency materials, particularly polymers, even contain multiple chemical building blocks in a donor-acceptor (D-A) arrangement. ${ }^{25-27} \mathrm{~A}$ relative stability ranking of some chemical building blocks has been created by synthesizing D-A polymers from various combinations of common donor and acceptor units. ${ }^{28}$ While work of this type provides synthetic chemists with helpful empirical guidelines, it does not address why some building units are more stable than others. In addition to the functional groups on the conjugated backbone, solution-processed OSC materials contain solubilizing side chains that can also impact stability. The role of the side chains in photo-degradation, particularly in photo-oxidation, is well established. ${ }^{18,29,30}$ For several polymers investigated in detail, ${ }^{22,31,32}$ one of the key steps in a photo-degradation reaction pathway is abstraction of a hydrogen atom on the alpha carbon of the solubilizing side chain, and polymers with thermocleavable side chains are observed to be more stable to photobleaching. ${ }^{33}$ Thus, both the molecular structure of the backbone and the solubilizing side chain can have a strong impact on observed stability.

In addition to the chemical structure, the molecular arrangement of materials in the solid state can impact stability. From the study of organic molecular crystals, it is well known that the physical constraints of the solid state, such as the inability of molecules to adopt different conformations, can dramatically change not only the rates of reaction, but also the products that can form. ${ }^{34}$ When considering solid state photochemistry, it is important to consider that the molecular arrangement and local environment of a molecule or polymer can be more important than the innate reactivity of the molecule or polymer itself. ${ }^{34}$ Given such a dependence on local environment and molecular arrangement, film morphology should have a strong effect on an observed photoreaction rate. A film's density, which is impacted by its degree of crystallinity, affects the permeability of chemical reactants to a reaction site and products away from it. Furthermore, the packing in a crystal structure limits the extent to which a polymer chain or molecule can rotate or change shape to reach intermediate or final chemical structures. The molecular packing may also increase the chemical strength of the bonds, especially if packing induces more rigid, planar backbones. Extended regions of delocalization should be chemically more robust. ${ }^{35}$

By comparing several polymer OSC materials, it has been observed that polymers with a higher degree of crystallinity tend to be more stable to photobleaching, ${ }^{36}$ though differences in chemical composition among materials may also influence the stability. The chemical composition of regioregular P3HT and regiorandom $\mathrm{P} 3 \mathrm{HT}$ is the same (Chart 1), yet regiorandom P3HT photobleaches at a faster rate. ${ }^{36,37}$ The difference between the materials is in the molecular conformation and film morphology; regioregular P3HT forms semicrystalline films, while regiorandom $\mathrm{P} 3 \mathrm{HT}$ polymer chains are highly twisted and films are completely disordered. ${ }^{38}$ Both the generality of this observation across OSC materials, and the underlying mechanisms that lead to the stabilizing effect of a more ordered film morphology, need to be explored further.

In this report, we investigate the role of film morphology and molecular conformation on the photooxidative stability of OSC materials. To probe the photooxidative stability, we illuminate neat films of a variety of OSC materials in air and track the optical absorption bleaching over time. Across the set of materials tested, we observe the bleaching rate to span seven orders of magnitude. For all films in which we can tune the morphology, we find that amorphous films photobleach faster than crystalline ones. We investigate factors that may lead to the large spread of photo-oxidative stabilities across materials, as well as the improved stability of crystalline films that are observed. Across all materials, we find that photo-oxidative stability tends to increase with film density. We also investigate the relationship between molecular conformation and photo-oxidative reactivity. We show that the relatively planar polymer poly(benzo[1,2- $b: 4,5-b$ ]dithiophene-thieno[3,4-c]pyrrole4,6 -dione) (PBDTTPD) ${ }^{39-42}$ is more photostable than its more twisted, less ordered benzodifuran derivative, poly(benzo[1,2-b:4,5-b']difuran-thieno[3,4-c]pyrrole-4,6dione) (PBDFTPD) ${ }^{43}$. Overall, we find that achieving the highest photochemical stability requires that dense, crystalline, and planar materials be designed for OSCs.

\section{Results}

\subsection{Photobleaching Films in Air}

In order to characterize the photochemical stability across materials, films of a variety of OSC materials were illuminated under ambient conditions in air by a LG sulfur plasma lamp with an intensity of $100 \mathrm{~mW} / \mathrm{cm}^{2}$. The lamp's spectrum closely matches the visible portion of the AM1.5G spectrum but has little ultraviolet radiation (Supplemental S1). Absorption spectra were periodically measured to track the decrease in thin film absorption with time (Supplemental Section 3). Films had an initial optical density (OD) of around 0.3 to ensure similar illumination throughout the thickness of the films for the duration of the experiment. In order to compare the photo-oxidative rate between materials, the normalized OD loss per hour was calculated by fitting the initial decay of the absorption maxima and normalizing by the initial peak absorption before ageing. ${ }^{44}$

Chart 1: The chemical structures of the investigated materials. 


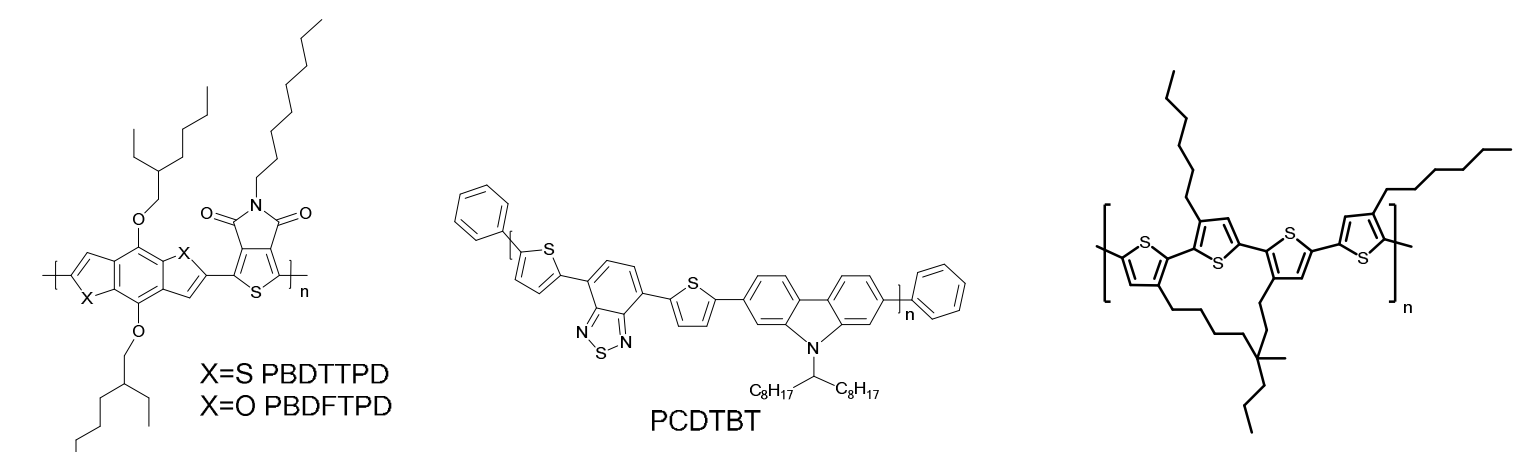

Regiorandom P3HT

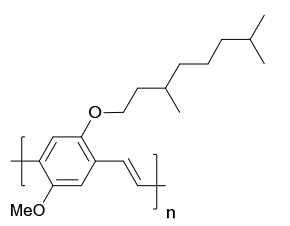

MDMO-PPV

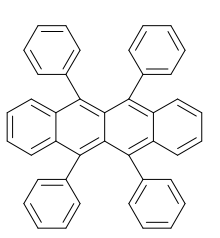

Rubrene

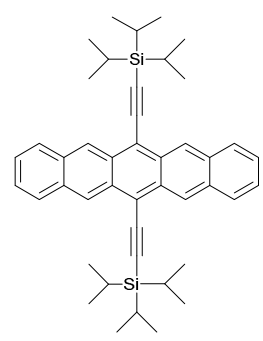

TIPS-Pentacene

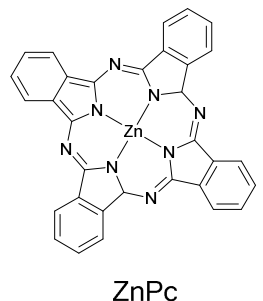

$\mathrm{ZnPC}$

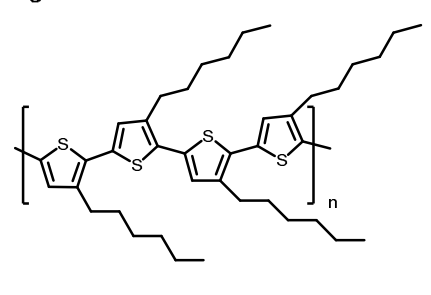

Regioregular P3HT
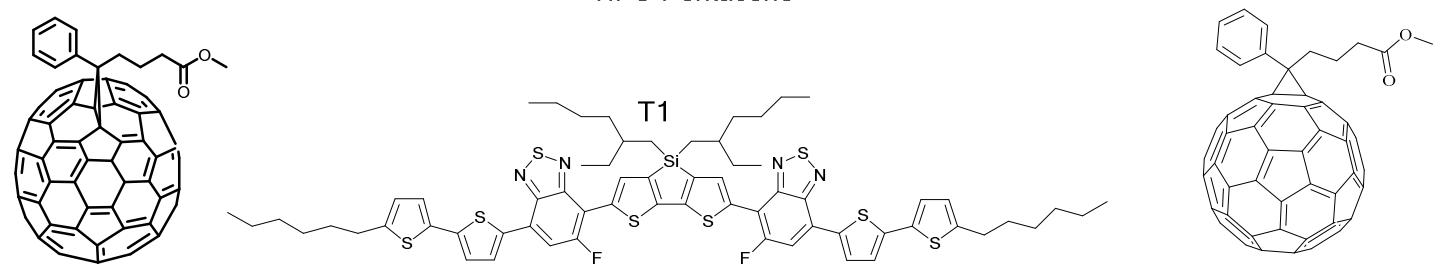

PCBM

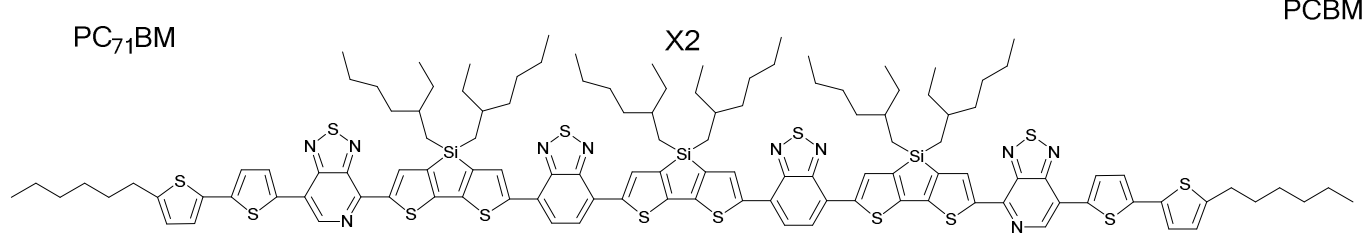

Among the materials we test, the photobleach rate spans seven orders of magnitude (Figure 1). Films of amorphous rubrene are the least stable with a bleach rate of about $16,000 \%$ per hour, which corresponds to complete bleaching in seconds. Of the polymers we investigate, poly[2-methoxy-5-(3',7'-dimethyloctyloxy)-1,4-

phenylenevinylene] (MDMO-PPV) (Chart 1) is the least stable and photobleaches at a rate of $500 \%$ per hour, which is about 250 times faster than the most stable polymer, PBDTTPD. The solution-processed small molecules $\quad 7,7^{\prime}$-(4,4-bis(2-ethylhexyl)-4H-silolo[3,2-b:4,5b'dithiophene-2,6-diyl)bis(6-fluoro-4-(5'-hexyl-[2,2'bithiophen]-5-yl)benzo[c][1,2,5]thiadiazole) $(\mathrm{T} 1)^{45}$ and $X 2^{46}$ (Chart 1), both of which can achieve $7 \%$ efficiency in OSCs, are slightly more stable than PBDTTPD, and bleach at rates just under $1 \%$ per hour. Finally, the materials with the lowest photobleach rate that we observe are the fullerene molecules PCBM and $\mathrm{PC}_{71} \mathrm{BM}$ and the evaporated small molecule zinc phthalocyanine $(\mathrm{ZnPc})$ (Chart 1), which lose OD at a rate of $0.1 \%$ per hour.

\subsection{Film Morphology and Photobleach Rate}

As has been previously observed, we find regioregular $\mathrm{P} 3 \mathrm{HT}$ to photobleach at a rate three to five times slower than regiorandom $\mathrm{P} 3 \mathrm{HT}, 4 \%$ versus $12 \%$ per hour, respectively. ${ }^{20,36,37}$ These two polymers have the same chemical composition, but differ in molecular conformation and thin film morphology. Regioregular P3HT develops into a semicrystalline film morphology, while regiorandom $\mathrm{P} 3 \mathrm{HT}$ has a twisted backbone and forms a completely disordered film.

In order to systematically explore the generality of the stabilizing effect of a more crystalline film morphology, and to control for differences in chemical structure among materials, we compared the stability of amorphous and crystalline films for several OSC materials. We specifically chose to investigate solutionprocessed and evaporated small molecules, as film morphologies are more easily tunable than in polymeric systems. Amorphous films of 6,13bis(triisopropylsilylethynyl)pentacene (TIPSpentacene), ${ }^{47} \mathrm{PCBM}, \mathrm{PC}_{71} \mathrm{BM}$, and $\mathrm{T} 1$ were prepared by spin-casting 


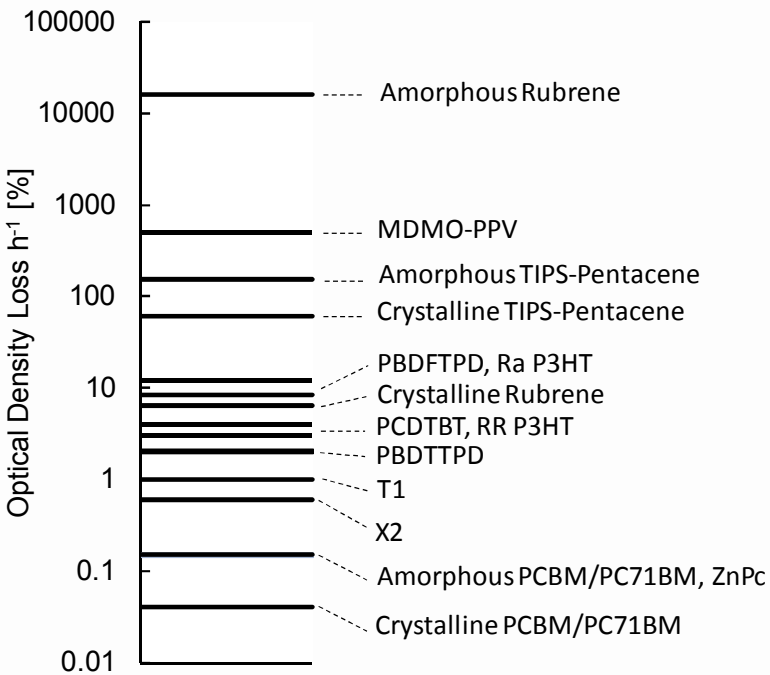

Figure 1. The optical density loss per hour in accelerated photobleaching for each investigated material. The magnitude of the photobleach rate varies across materials by 7 orders.

the materials from chloroform or chlorobenzene solutions, and crystallinity was induced by thermal annealing. Amorphous films of rubrene were prepared by evaporating at a fast rate, and crystallinity was similarly induced by annealing. Morphologies were compared using grazing incidence X-ray diffraction (Supplemental Section 2). Detailed morphological characterization was not used to determine degree of crystallinity, crystallite size, or crystallite orientation; films of the same material were simply categorized as "amorphous" or "crystalline" based on the appearance of diffraction spots in the diffraction patterns. To minimize any effect of batch-to-batch impurity levels, we fabricated amorphous films of each material on glass substrates, which we broke in half. We annealed one half to induce crystallinity, while the other remained amorphous. We then illuminated the crystalline and amorphous films side-by-side, took absorption spectra over time, and tracked the OD loss.

For every material that could be made as both amorphous and crystalline films, the films with a crystalline morphology are more stable (Table 1). The photobleach rates observed in crystalline films are slower than the rates of amorphous films by a factor of three to five for most of the materials. Notably, while amorphous films of rubrene are the least stable material we observe and lose OD at a

Table 1. Crystalline Films Improvement in Stability

\begin{tabular}{|l|l|}
\hline Material & $\begin{array}{l}\text { Ratio of Photobleach Rate of } \\
\text { Crystalline Film }\end{array}$ \\
\hline $\begin{array}{l}\text { TIPS- } \\
\text { Pentacene }\end{array}$ & 2.5 \\
\hline T1 & 3 \\
\hline P3HT & 3 \\
\hline Fullerenes & 4 \\
\hline Rubrene & $>2500$ \\
\hline
\end{tabular}

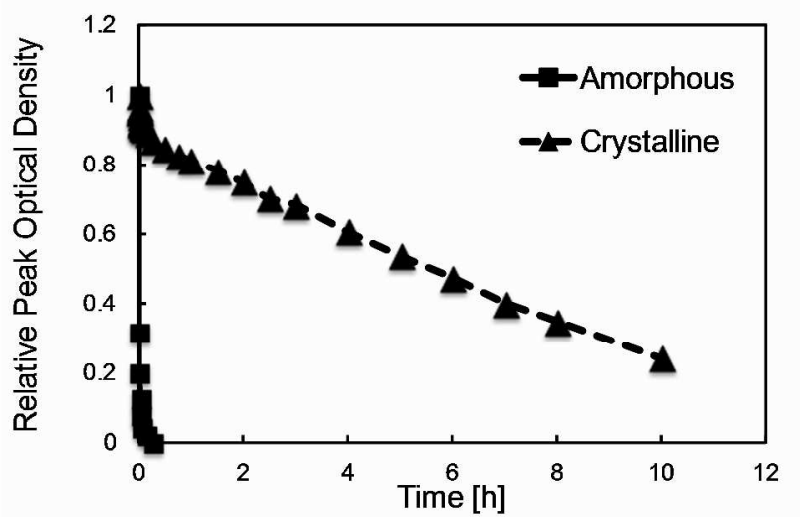

Figure 2. The normalized peak optical density versus time is plotted for both amorphous and crystalline rubrene films. Amorphous rubrene films completely bleach in minutes, while crystalline films bleach over hours.

rate of $16,000 \%$ per hour, crystalline films have photobleach rates equivalent to many of the polymers we test, at about $6 \%$ per hour (Figure 2). The factor of stability improvement in crystalline rubrene films is over 2500.

\subsection{Film Density and Photobleach Rate}

Physical constraints, such as limited molecular motion and atomic mobility, could be at the origin of the difference in stability between the disordered and crystalline morphologies, as well as partially account for the large variation in photobleach rate observed across all materials. Materials with higher crystallinity are generally denser than more amorphous materials, and an increased density could lower the permeability of chemical reactants and products. This effect has been observed previously in semicrystalline polymers like polyketones and polyethylene, where both the solubility and diffusivity of gases are inversely proportional to the degree of crystallinity. ${ }^{48-53}$ It has also been shown that in semiconducting polymers with a higher degree of crystallinity, oxygen is less efficient at quenching photogenerated triplet states, which may imply that oxygen molecules are not able to penetrate semicrystalline films as easily as amorphous ones. ${ }^{36}$ Furthermore, one strategy used to improve the weatherability of organic pigments has been to increase their density. ${ }^{54,55}$ Dense packing in organic pigments prevents molecules from changing shape and adopting new molecular conformations, and photoinduced radicals are physically confined and often simply recombine without further reaction. ${ }^{56}$ In the context of polymers, for which the first step of photo-oxidation can be hydrogen abstraction on the side chains leading to radical formation, improving the side chain packing or increasing the density of the film could lead to radical recombination instead of further reaction along the conjugated backbone.

To examine the possible connection between film density and photobleach rate, we measured the density of thin films for the materials we aged using Xray reflectivity (Table 2 ), which can be used to estimate the density and thickness of thin films. At values of theta below the critical angle of the film, the X-rays are completely reflected off the 


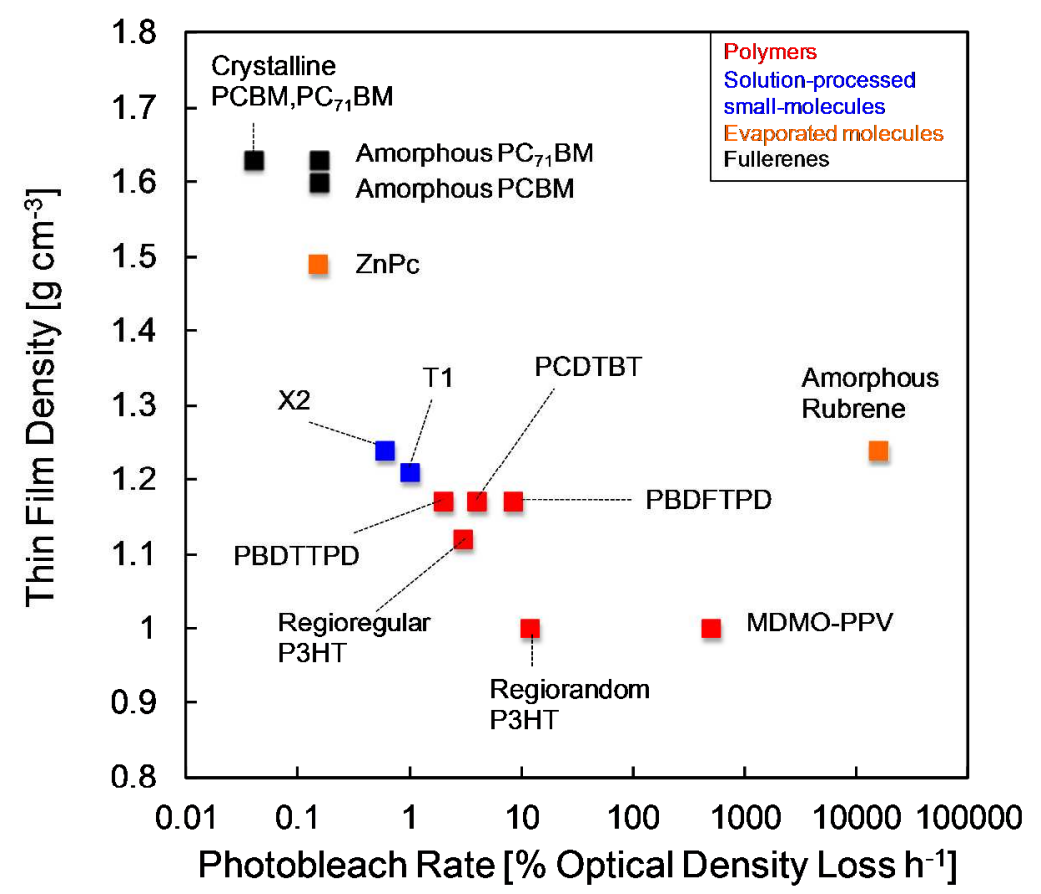

Figure 3. Thin film density plotted against the photobleach rate for the materials investigated. As a general trend, the films with the slowest degradation are also the densest. An outlier is "amorphous rubrene", which has the highest photobleach rate while its density remains somewhat high compared to more stable systems.

surface. At the film's critical angle, which is a function of the film's density, there is a sharp drop in measured intensity, as the X-rays are no longer reflected off the surface. Between the critical angle of the film and the substrate, the X-rays pass through the film thickness and are internally reflected off the substrate, and give rise to interference fringes which are a function of the film's thickness. (Supplemental Section 4 for more details) MDMO-PPV, the least stable polymer, has a density of about $1.00 \mathrm{~g} \mathrm{~cm}^{-3}$. Regioregular $\mathrm{P} 3 \mathrm{HT}$ that has been melted and slowly cooled to room temperature to induce crystallinity has a density of $1.12 \mathrm{~g} \mathrm{~cm}^{-3}$, which is denser than both as-cast regioregular $\mathrm{P} 3 \mathrm{HT}$ and regiorandom $\mathrm{P} 3 \mathrm{HT}$. PCDTBT and PBDTTPD are even denser, at close to $1.17 \mathrm{~g} \mathrm{~cm}^{-3}$. Films of the solution-processed small molecules $\mathrm{T} 1$ and $\mathrm{X} 2$ have densities higher than $1.20 \mathrm{~g} \mathrm{~cm}^{-3}$. Finally, PCBM and $\mathrm{PC}_{71} \mathrm{BM}$ are the densest materials in the present study, at over $1.60 \mathrm{~g} \mathrm{~cm}^{-3}$. Unlike the polymer films, the difference in density between the crystalline and amorphous small molecule films could not be resolved and were within the error of the measurement. Chains of disordered polymers likely occupy a large volume compared to ordered polymer chains, which become more like packed rods than disordered coils. It is likely that the small molecules do not have the same rotational freedom in the disordered state to occupy significantly more volume than in the crystalline state, and so the difference in density is minimized compared to polymers.

When plotted against the photobleaching rate, there is a clear correlation between density and photooxidation (Figure 3 ). Denser films, especially above 1.50 $\mathrm{g} \mathrm{cm}^{-3}$, photobleach at a slower rate than films that are less dense. These results suggest a relation between density and stability. The correlation is not absolute; factors in addition to film density, such as specific chemical groups, could account for some of the discrepancies. For exam

Table 2. Material Densities Obtained from X-ray Reflectivity

\begin{tabular}{|c|c|}
\hline Material & $\begin{array}{l}\text { Density } \quad\left[\mathrm{g}^{\mathrm{cm}} \mathrm{cm}^{-3}\right] \quad( \pm \\
0.05)\end{array}$ \\
\hline MDMO-PPV & 1.00 \\
\hline Regiorandom P3HT & 1.00 \\
\hline Regioregular P3HT & 1.00 \\
\hline $\begin{array}{ll}\text { Annealed } & \text { Regioregular } \\
\text { P3HT } & \end{array}$ & 1.12 \\
\hline PBDFTPD & 1.12 \\
\hline PCDTBT & 1.16 \\
\hline PBDTTPD & 1.17 \\
\hline $\mathrm{T} 1^{\mathrm{a}}$ & 1.21 \\
\hline $\mathrm{X} 2$ & 1.24 \\
\hline Rubrene $^{a}$ & 1.24 \\
\hline $\mathrm{ZnPc}$ & 1.49 \\
\hline PCBM $^{a}$ & 1.60 \\
\hline $\mathrm{PC}_{71} \mathrm{BM}^{\mathrm{a}}$ & 1.63 \\
\hline
\end{tabular}

a) The measured density of amorphous and crystalline films lies within the error. 

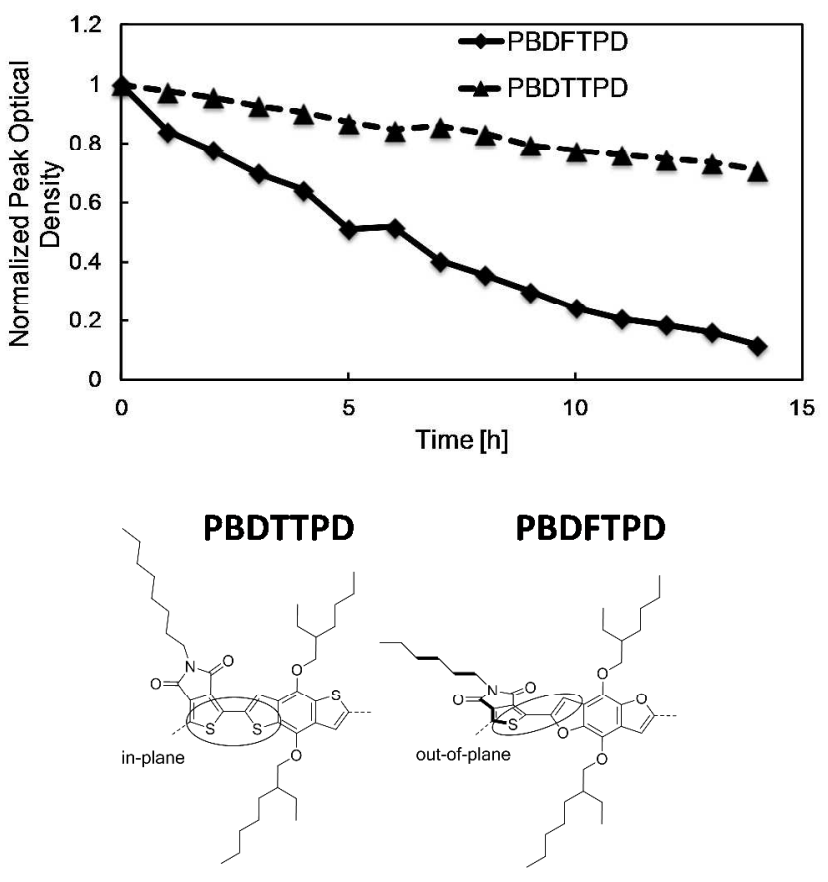

Figure 4. (Top) The normalized peak absorbance versus time is shown for PBDTTPD and PBDFTPD. PBDFTPD is less stable. (Bottom) The structures of PBDTTPD and PBDFTPD are shown. The BDT and TPD units lie in the same plane, while the BDF and TPD units twist out of plane.

ple, MDMO-PPV and regiorandom P3HT differ in stability by two orders of magnitude. This difference is likely due to the presence of a vinylene group on MDMO-PPV, which is known to be highly reactive. ${ }^{57}$ PCDTBT, PBDTTPD, and PBDFTPD also have similar densities, but different photobleach rates. A more extreme outlier is amorphous rubrene, which is by far the most reactive material, while comparable in density to $\mathrm{T} 1$ and $\mathrm{X} 2$. This may be due to the molecular conformation that rubrene molecules adopt in the amorphous state.

\subsection{Bond Twisting and Photobleach Rate}

In addition to the physical constraints imposed by a crystal structure, the innate chemical reactivity of the OSC materials may also be changed in the crystalline state. The bonds of conjugated cores are stabilized by the delocalization and resonance energy of the pi electrons. ${ }^{35}$ Any disruption of this delocalization, for instance by a twist in the backbone of the material, weakens the bonds and should cause the reactivity to increase. Models of amorphous rubrene show it to have a backbone twist of $42^{\circ}$, while molecules in a crystal are completely planar, ${ }^{58}$ which may explain such an extreme improvement in stability in the crystalline state.

The polymer with the lowest observed photobleach rate in the present study is PBDTTPD. Photostability of PBDTTPD has been observed by others, and its stability compared to P3HT and PCDTBT, which have similar densities, has been hypothesized to result from the presence of oxy-alkyl side chains, ${ }^{59}$ which have been predicted to be more stable to photo-oxidation than simple alkyl side chains. ${ }^{60}$ Another factor that may contrib- ute to its enhanced stability is its planarity. PBDTTPD is predicted by models to be almost completely planar, ${ }^{61}$ possibly aided by intermolecular interactions between the oxygen on the TPD unit and a hydrogen on the BDT unit. ${ }^{6}$ To investigate the effect of backbone twisting on photo-stability, we compared the photobleaching rates of PBDTTPD and its furan derivative, PBDFTPD (Figure 4). Films of the two polymers have similar densities of 1.16 and $1.12 \mathrm{~g} \mathrm{~cm}^{-3}$. When the benzodithiophene unit of PBDTTPD is replaced by a benzodifuran unit to form PBDFTPD, the highest occupied molecular orbital of the polymer is further from vacuum (PBDTTPD is reportedly $5.29 \mathrm{eV}$ and PBDFTPD is $5.41 \mathrm{eV}$ ), and the BDF and TPD units can twist out-of-plane, which is the most notable differences between the two polymers. ${ }^{43}$ In our sideby-side comparison of similarly prepared polymer batches, PBDTTPD loses OD at a rate four times slower than PBDFTPD. While a material's stability is probably affected by a combination of chemical structure and molecular conformation, the results of this particular experiment suggest that a chemical change that induces a more twisted conformation can have a strong effect on photooxidative stability.

\section{Discussion}

\subsection{Accelerating Degradation}

Ultimately, accelerated degradation experiments should represent the same degradation mechanisms as normal operating conditions. In photobleaching experiments in air, the condition that accelerates the observed degradation is environmental oxygen concentration. It is important to consider how photo-oxidation contributes to OSC degradation that has so far been observed. Though the severity of burn-in depends on film morphology, ${ }^{63}$ at least in OSCs made with PCDTBT, reactions with oxygen do not appear to cause burn-in, as the solar cells lose nearly $40 \%$ of starting efficiency to burn-in in an environment with less than $0.1 \mathrm{ppm}$ oxygen. ${ }^{14}$ Long-term stability, however, does appear to be affected by environmental oxygen content, as post burn-in degradation is minimal in the solar cells made with PCDTBT and aged in the same low oxygen environment. ${ }^{14}$ In a simple model where photo-oxidation of PCDTBT is first order dependent on oxygen concentration, the observed rate of photo-oxidation compared to air should be reduced by a factor of $2.05 \times 10^{6}$ in an environment with $0.1 \mathrm{ppm} \mathrm{O}_{2}$. A defect concentration of $0.01-0.1 \%$ is known to reduce solar cell performance by $20-50 \%,{ }^{64,65}$ and with a photobleach rate of $4 \%$ per hour, the illumination time needed to photochemically introduce such a number of defects (corresponding $0.01-0.1 \%$ bleach of PCDTBT) in an environment with $0.1 \mathrm{ppm} \mathrm{O}$ is $5100-51000 \mathrm{~h}$ (SI for details). This simple "back-of-the envelope" calculation matches the observed lifetime $(41000 \mathrm{~h})$ of PCDTBT solar cells in such an environment.

In a solar cell with more realistic packaging, oxygen will first need to diffuse through the packaging material and then chemically react with the OSC material. Either step could be degradation rate limiting. Based on the measured density and photobleach rate, a thin film of unpackaged PCDTBT in air consumes oxygen via photoreaction at a rate of $3.05 \mathrm{~cm}^{3} \mathrm{~m}^{-2} \mathrm{day}^{-1}$ (SI for details). Thus, the oxygen consumption of the PCDTBT will only 
be the rate limiting step in OSC degradation if oxygen permeation through a barrier film is faster. Untreated films of poly(ethylene terephthalate) (PET), poly(ethersulfone) (PES), and poly(ethylene-2,6naphthalate) (PEN) have oxygen transport rates (OTRs) of the same order of magnitude as the oxygen consumption of PCDTBT, and improvement in the photo-oxidative stability of the semiconductor should lead to improvement of the stability of the packaged OSC. ${ }^{66}$ However, a layer of inorganic material is typically deposited onto a PEN or PET substrate, which reduces the OTR of the composite barrier films by 2-3 orders of magnitude. Glass-on-glass packaging provides even lower OTR. In these cases, the rate limiting step of OSC photooxidation will be diffusion of oxygen through the barrier film, and the measured lifetime will be determined more from the quality of the packaging than the photooxidative stability of the semiconductor. In the context of this work, the improved photo-oxidative stability of more crystalline organic semiconductors will improve OSC lifetimes in applications that employ packaging that is more permeable to oxygen.

3.2 Photochemical Reactions in the Absence of Oxygen and Water

Stiff molecules with denser, more crystalline morphologies should impact the chemical stability of OSCs even in the absence of oxygen and water. OLEDs can serve as an example, as they are similarly packaged and chemical degradation mechanisms beyond oxidation have been reported. ${ }^{67,68}$ Detailed mechanistic studies have shown twisted or freely rotating bonds to disassociate under irradiation and operation. ${ }^{67,69,70}$ Lifetimes are improved by a factor of 4-200 in OLED devices that incorporate stiff molecules that strongly aggregate, ${ }^{71,72}$ even when the chemical degradation mechanism does not involve oxygen. Generally, OLED lifetimes have improved enough to enter the commercial market, and a review of some of the latest OLED materials shows a trend of more planar, stiffer molecules. ${ }^{73}$ The progress in OLEDs further supports the idea that the general chemical stability of OSCs could also benefit from stiffer molecules with denser, more crystalline morphologies.

\section{Conclusions}

In summary, as the photobleach rate of OSC materials spans seven orders of magnitude, design rules are needed to direct synthetic efforts towards new materials with high stability. Material engineering to enhance crystallinity has helped improve the stability of organic materials in other functions, such as structural polymers, and in this study we have shown that crystalline OSC films are generally more stable than amorphous ones. Moving forward, new materials should be designed to form ordered crystalline domains. Crystal engineering of organic pigments to increase density has already been shown to improve resistance to weathering, and we find that photobleaching rates correlate with OSC material density. Thus, new materials should be designed to be as dense as possible. Evaporated molecules are likely the best path to films with high density, as there are tradeoffs between solution-processability and material density. Finally, stable OLED materials are trending towards planar, stiffer molecules, and our study is con- sistent with this idea, showing that a backbone twist in $\pi$ conjugated systems can accelerate the photobleaching rate and compromise long-term stability in OSC materials. Materials design towards dense, crystalline films of planar, stiff molecules should increase the observed stability of OSC materials and devices.

\section{Experimental Section}

Materials: $\mathrm{PCBM}$ and $\mathrm{PC}_{71} \mathrm{BM}$ were purchased from Solenne. MDMO-PPV, rubrene, TIPS-pentacene, pentacene, and $\mathrm{ZnPc}$ were purchased from Sigma Aldrich. Regioregular P3HT was purchased from BASF. Regiorandom $\mathrm{P} 3 \mathrm{HT}$ was purchased from Rieke. PCDTBT was purchased from St. Jean Photochemie. PBDTTPD and PBDFTPD were synthesized similarly to Warnan et al and were prepared to have similar molecular weights. ${ }^{43}$ T1 and X2 were synthesized similarly to van der Poll et al. $^{45}$ and Liu et al., ${ }^{46}$ respectively. All materials were studied as received without additional purification.

Sample Preparation and Ageing: Glass substrates were scrubbed with dilute Extran 3000 detergent and ultrasonicated in dilute Extra 3000 detergent, acetone, and isopropyl alcohol for 15 minutes each. Films of PCBM, $\mathrm{PC}_{71} \mathrm{BM}$, TIPS-pentacene, $\mathrm{X} 2$, regioregular and regiorandom $\mathrm{P} 3 \mathrm{HT}$ were spin-cast onto the glass substrates from chloroform solutions to form amorphous films. PCDTBT was spin-cast from dichlorobenzene, and T1, PBDTTPD, and PBDFTPD were spin-cast from chlorobenzene. Amorphous rubrene was prepared by thermal evaporation onto substrates at a rate of $5.0 \AA / \mathrm{s}$ at a pressure of $1.0 \times 10^{-6}$ Torr. ZnPc was thermally evaporated onto substrates at $1.0 \AA / \mathrm{s}$ at a pressure of $1.0 \times$ $10^{-6}$ Torr. Initial peak optical densities of the films were about 0.3. To induce crystallinity, films of PCBM, $\mathrm{PC}_{71} \mathrm{BM}$, and $\mathrm{T} 1$ were annealed at $180{ }^{\circ} \mathrm{C}$ for 20 minutes, films of TIPS-pentacene were annealed at 175 ${ }^{\circ} \mathrm{C}$ for 20 minutes, rubrene films were annealed at 100 ${ }^{\circ} \mathrm{C}$ for $98 \mathrm{~h}$, and regioregular $\mathrm{P} 3 \mathrm{HT}$ films were annealed at $220{ }^{\circ} \mathrm{C}$ and slow cooled to room temperature. For direct comparison between amorphous and crystalline films of each material, amorphous samples were broken in half, and one half was annealed. Samples were aged in air under a sulfur-plasma lamp (LG 6000K) with an intensity of $100 \mathrm{~mW} \mathrm{~cm}^{-2}$ and a temperature of $40{ }^{\circ} \mathrm{C}$. The humidity was not controlled. From data taken at a weather station on Stanford campus and made available at wunderground.com over the period of January 1, 2014 to December 31, 2014, the dew point varies month-tomonth but stays within the range of $40-60{ }^{\circ} \mathrm{F}$ (see Supplemental). This corresponds to a water content of $8,000-17,500$ ppm on a volume basis. The humidity of the indoor lab was most likely within that range. The amorphous and crystalline halves from the same substrate were illuminated side by side. UV-vis absorption spectra were measured in transmission mode with an Ocean Optics DT-1000-CE UV-Vis spectrometer. The time corresponding to the first $5-30 \%$ of photobleaching was used to determine the photobleach rate.

$X$-Ray Diffraction: Films were prepared on glass substrates in the same conditions as ageing. Grazing incidence X-ray scattering (GIXS) was obtained at beamline 11-3 at the Stanford Synchotron Radiation Lightsource using an X-ray energy of $12.7 \mathrm{eV}$, a MAR 345 image 
plate area detector, a helium-filled sample chamber, with an incident X-ray beam angle of $0.12^{\circ}$.

Density Measurements: Densities of the various materials were obtained from X-ray reflectivity scans. Neat films were prepared on either silicon or glass substrates. Films were taken to beamline 2-1 at the Stanford Synchrotron Radiation Lightsource (SSRL). Low angle thetatwo theta scans from theta $0.1^{\circ}-0.3^{\circ}$ were collected using a beam energy of $8000 \mathrm{eV}$. The curve fitting program IMD 5.0 was used to fit densities to the various films. ${ }^{74}$ To achieve the best fits, the film thicknesses and densities were manually adjusted.

\section{ASSOCIATED CONTENT}

Supporting Information. Grazing Incidence X-ray Diffraction and sample calculations are in the supporting information. This material is available free of charge via the Internet at http://pubs.acs.org.

\section{AUTHOR INFORMATION}

\section{Corresponding Author}

E-mail: mmcgehee@stanford.edu

\section{Author Contributions}

The manuscript was written through contributions of all authors. All authors have given approval to the final version of the manuscript.

\section{Funding Sources}

Office of Naval Research Award numbers N00014-14-10580 and N00014-14-1-0280

\section{ACKNOWLEDGMENT}

This publication was supported by the Office of Naval Research (ONR Award numbers N00014-14-1-0580 and N00014-14-1-0280). We also thank LG for providing the sulfur plasma lamps. TH gratefully acknowledges a "DAAD Doktorandenstipedium" and the SFB 953 "Synthetic Carbon Allotropes".

\section{REFERENCES}

(1) Liu, Y.; Zhao, J.; Li, Z.; Mu, C.; Ma, W.; Hu, H.; Jiang, K.; Lin, $H_{\text {.; }}$ Ade, H.; Yan, H. Aggregation and Morphology Control Enables Multiple Cases of High-Efficiency Polymer Solar Cells. Nat. Commun. 2014.

(2) Kan, B.; Zhang, Q.; Li, M.; Wan, X.; Ni, W.; Long, G.; Wang, Y.; Yang, X.; Feng, H.; Chen, Y. SolutionProcessed Organic Solar Cells Based on DialkylthiolSubstituted Benzodithiophene Unit with E Ffi Ciency near 10\%. J. Am. Chem. Soc. 2014, 136, 15529-15532.

(3) Heliatek. Heliatek consolidates its technology leadership by establishing a new world record for organic solar technology with a cell efficiency of $12 \%$ http://www.heliatek.com/wpcontent/uploads/2013/01/130116_PR_Heliatek_achieves record_cell_effiency_for_OPV.pdf.

(4) Green, M. A.; Emery, K.; Hishikawa, Y.; Warta, W.; Dunlop, E. D. Solar Cell Efficiency Tables (version 44). Prog. Photovoltaics Res. Appl. 2014, 22, 701-710.
(5) Zhou, H.; Zhang, Y.; Mai, C.-K.; Collins, S. D.; Bazan, G. C.; Nguyen, T.-Q.; Heeger, A. J. Polymer Homo-Tandem Solar Cells with Best Efficiency of $11.3 \%$. Adv. Mater. 2015.

(6) Subbiah, J.; Purushothaman, B.; Chen, M.; Qin, T.; Gao M.; Vak, D.; Scholes, F. H.; Chen, X.; Watkins, S. E.; Wilson, G. J.; et al. Organic Solar Cells Using a HighMolecular-Weight Benzodithiophene-Benzothiadiazole Copolymer with an Efficiency of 9.4\%. Adv. Mater. 2014, 27, 702-705.

(7) Sun, K.; Xiao, Z.; Lu, S.; Zajaczkowski, W.; Pisula, W.; Hanssen, E.; White, J. M.; Williamson, R. M.; Subbiah, J.; Ouyang, J.; et al. A Molecular Nematic Liquid Crystalline Material for High-Performance Organic Photovoltaics. Nat. Commun. 2015.

(8) Jørgensen, M.; Norrman, K.; Gevorgyan, S. A.; Tromholt T.; Andreasen, B.; Krebs, F. C. Stability of Polymer Solar Cells. Adv. Mater. 2012, 24, 580-612.

Grossiord, N.; Kroon, J. M.; Andriessen, R.; Blom, P. W. $M$. Degradation Mechanisms in Organic Photovoltaic Devices. Org. Electron. 2012, 13, 432-456.

Blouin, N.; Michaud, A.; Gendron, D.; Wakim, S.; Blair, E.; Neagu-plesu, R.; Bellete, M.; Durocher, G.; Tao, Y.; Leclerc, M. Toward a Rational Design of Poly ( 2 , 7Carbazole ) Derivatives for Solar Cells. J. Am. Chem. Soc. 2008, 130, 732-742.

Peters, C. H.; Sachs-Quintana, I. T.; Kastrop, J. P.; Beaupré, S.; Leclerc, M.; McGehee, M. D. High Efficiency Polymer Solar Cells with Long Operating Lifetimes. Adv. Energy Mater. 2011, 1, 491-494.

Roesch, R.; Eberhardt, K.-R.; Engmann, S.; Gobsch, G.; Hoppe, H. Polymer Solar Cells with Enhanced Lifetime by Improved Electrode Stability and Sealing. Sol. Energy Mater. Sol. Cells 2013, 117, 59-66.

Mateker, W. R.; Sachs-Quintana, I. T.; Burkhard, G. F.; Cheacharoen, R.; McGehee, M. D. Minimal Long-Term Intrinsic Degradation Observed in a Polymer Solar Cell Illuminated in an Oxygen-Free Environment. Chem. Mater. 2015, 404-407.

Hermenau, M.; Riede, M.; Leo, K. Degradation of SmallMolecule-Based OPV. In Stability and Degradation of Organic and Polymer Solar Cells; Krebs, F. C., Ed.; John Wiley and Sons: Chichester, UK, 2012; pp. 109-142.

(16) Peters, C. H.; Sachs-Quintana, I. T.; Mateker, W. R.; Heumueller, T.; Rivnay, J.; Noriega, R.; Beiley, Z. M.; Hoke, E. T.; Salleo, A.; McGehee, M. D. The Mechanism of Burn-in Loss in a High Efficiency Polymer Solar Cell. Adv. Mater. 2012, 24, 663-668.

Kong, J.; Song, S.; Yoo, M.; Lee, G. Y.; Kwon, O.; Park, J. K.; Back, H.; Kim, G.; Lee, S. H.; Suh, H.; et al. LongTerm Stable Polymer Solar Cells with Significantly Reduced Burn-in Loss. Nat. Commun. 2014. 
(18) Rivaton, A.; Tournebize, A.; Gaume, J.; Bussière, P.-O.; Gardette, J.-L.; Therias, S. Photostability of Organic Materials Used in Polymer Solar Cells. Polym. Int. 2014, 63, 1335-1345.

(19) Sai, N.; Leung, K.; Zádor, J.; Henkelman, G. First Principles Study of Photo-Oxidation Degradation Mechanisms in P3HT for Organic Solar Cells. Phys. Chem. Chem. Phys. 2014, 16, 8092-8099.

(21) Reese, M. O.; Nardes, A. M.; Rupert, B. L.; Larsen, R. E.; Olson, D. C.; Lloyd, M. T.; Shaheen, S. E.; Ginley, D. S.; Rumbles, G.; Kopidakis, N. Photoinduced Degradation of Polymer and Polymer-Fullerene Active Layers: Experiment and Theory. Adv. Funct. Mater. 2010, 20, 3476-3483.

(22) Chambon, S.; Rivaton, A.; Gardette, J.; Firon, M.; Lutsen, L. Aging of a Donor Conjugated Polymer: Photochemical Studies of the Degradation of Poly [ 2-Methoxy-5-. J. Polym. Sci. A Polym. Chem. 2006, 45, 317-331.

(23) Rivaton, A.; Mailhot, B.; Derderian, G.; Bussiere, P. O.; Gardette, J.-L. Investigation of the Photophysical Films Irradiated at $\Lambda>300 \mathrm{Nm}$. Macromolecules 2003, 36, 5815-5824.

(24) Boudreault, P.-L. T.; Najari, A.; Leclerc, M. Processable Low-Bandgap Polymers for Photovoltaic Applications. Chem. Mater. 2011, 23, 456-469.

(25) Zhang, Q. T.; Tour, J. M. Alternating Donor / Acceptor Repeat Units in Polythiophenes . Intramolecular Charge Transfer for Reducing Band Gaps in Fully Substituted $5355-5362$.

(26) Beaujuge, P. M.; Fréchet, J. M. J. Molecular Design and Ordering Effects in П-Functional Materials for Transistor and Solar Cell Applications. J. Am. Chem. Soc. 2011, 133, 20009-20029.

(27) Zhang, Z.; Wang, J. Structures and Properties of Conjugated Donor-Acceptor Copolymers for Solar Cell Applications. J. Mater. Chem. 2012, 22, 4178-4187.

(28) Manceau, M.; Bundgaard, E.; Carlé, J. E.; Hagemann, O.; Helgesen, M.; Søndergaard, R.; Jørgensen, M.; Krebs, F. C. Photochemical Stability of $\Pi$-Conjugated Polymers for Polymer Solar Cells: A Rule of Thumb. J. Mater. Chem. 2011, 21, 4132-4141.

(30) Hintz, H.; Egelhaaf, H.-J.; Peisert, H.; Chassé, T. PhotoOxidation and Ozonization of poly(3-Hexylthiophene) Thin Films as Studied by UV/VIS and Photoelectron Spectroscopy. Polym. Degrad. Stab. 2010, 95, 818-825.

Rivaton, A.; Gardette, J.-L.; Mailhot, B.; Morlat-Therlas, S. Basic Aspects of Polymer Degradation. Macromol. Symp. 2005, 225, 129-146. Processes and Photochemical Reactions Involved in PVK Conjugated Polymers. J. Am. Chem. Soc. 1998, 120,

Bussière, P.-O.; Rivaton, A.; Thérias, S.; Gardette, J.-L. Multiscale Investigation of the poly(N-Vinylcarbazole) Photoageing Mechanism. J. Phys. Chem. B 2012, 116, 802-812.

Chambon, S.; Rivaton, A.; Gardette, J.; Firon, M. Reactive Intermediates in the Initiation Step of the Photo-Oxidation of MDMO-PPV. J. Polym. Sci. A Polym. Chem. 2009, 47, 6044-6052.

Manceau, M.; Helgesen, M.; Krebs, F. C. ThermoCleavable Polymers: Materials with Enhanced Photochemical Stability. Polym. Degrad. Stab. 2010, 95, 2666-2669.

(34) Ramamurthy, V.; Venkatesan, K. Photochemical Reactions of Organic Crystals. Chem. Rev. 1987, 87, 433-481.

Cabanetos, C.; Labban, A. El; Bartelt, J. A.; Douglas, J. D.; Mateker, W. R.; Fréchet, J. M. J.; Mcgehee, M. D.; Beaujuge, P. M. Linear Side Chains in Benzo[1,2-b:4,5B']dithiophene-Thieno[3,4-C]pyrrole-4,6-Dione Polymers Direct Self-Assembly and Solar Cell Performance. J. Am. Chem. Soc. 2013, 135, 4656-4659.

Warnan, J.; Cabanetos, C.; Labban, A. El; Hansen, M. R.; Tassone, C.; Toney, M. F.; Beaujuge, P. M. Ordering Effects in Benzo[1,2- B :4,5- B ']difuran-Thieno[3,4- C jpyrrole-4,6-Dione Polymers with $>7 \%$ Solar Cell Efficiency. Adv. Mater. 2014, 26, 4357-4362. 
Hoke, E. T.; Sachs-Quintana, I. T.; Lloyd, M. T.; Kauvar, I.; Mateker, W. R.; Nardes, A. M.; Peters, C. H.; Kopidakis, N.; McGehee, M. D. The Role of Electron Affinity in Determining Whether Fullerenes Catalyze or Inhibit Photooxidation of Polymers for Solar Cells. Adv. Energy Mater. 2012, 2, 1351-1357.

(45) Van der Poll, T. S.; Love, J. A.; Nguyen, T.-Q.; Bazan, G. C. Non-Basic High-Performance Molecules for SolutionProcessed Organic Solar Cells. Adv. Mater. 2012, 24 3646-3649.

(46) Liu, X.; Sun, Y.; Perez, L. A.; Wen, W.; Toney, M. F.; Heeger, A. J.; Bazan, G. C. Narrow-Band-Gap Conjugated Chromophores with Extended Molecular Lengths. J. Am. Chem. Soc. 2012, 134, 20609-20612.

(47) Sheraw, C. D.; Jackson, T. N.; Eaton, D. L.; Anthony, J. E. Functionalized Pentacene Active Layer Organic Thin-Film Transistors. Adv. Mater. 2003, 15, 2009-2011.

(48) Michaels, A. S.; Bixler, H. J. Flow of Gases through Polyethylene. J. Polym. Sci. 1961, 50, 413-439.

(49) Michaels, A. S.; Bixler, H. J. Solubility of Gases in Polyethylene. J. Polym. Sci. 1961, 50, 393-412.

(50) Hartley, H.; Guillet, J. E. Ketone Polymers. I. Studies of Ethylene-Carbon Monoxide Copolymers. Macromolecules 1968, I, 165-170.

(51) Hartley, G. H.; Guillet, J. E. Photochemistry of Ketone Polymers. II Studies of Model Compounds. Macromolecules 1968, I, 413-417.

(52) Torikai, A.; Geetha, R.; Nagaya, S.; Fueki, K. RadiationInduced Degradation of Polyethylene: Polymer Structure and Stability. J. Polym. Sci. Part A Polym. Chem. 1990, 28, 3639-3646.

(53) Geetha, R.; Torikai, A.; Yoshida, S.; Nagaya, S.; Shirakawa, H.; Fueki, K. Radiation-Induced Degradation of Polyethylene: Effect of Processing and Density on the Chemical Changes and Mechanical Properties. Polym. Degrad. Stab. 1988, 23, 91-98.

(54) Erk, P. Crystal Design of High Performance Pigments. In High Performance Pigments; Smith, H. M., Ed.; WileyVCH Verlag GmbH \& Co. KGaA, 2002; Vol. 8, pp. 103123.

(55) Nicolaou, C. High Performance Pigments; Smith, H. M., Ed.; 1st ed.; Wiley-VCH Verlag GmbH: Weinheim, 2003.

(56) Schmidt, M. U.; Hofmann, D. W. M.; Buchsbaum, C.; Metz, H. J. Crystal Structures of Pigment Red 170 and Derivatives, as Determined by X-Ray Powder Diffraction. Angew. Chemie 2006, 45, 1313-1317.

(57) Chambon, S.; Rivaton, A.; Gardette, J.-L.; Firon, M. Photo- and Thermal Degradation of MDMO-PPV:PCBM Blends. Sol. Energy Mater. Sol. Cells 2007, 91, 394-398.

(58) Käfer, D.; Witte, G. Growth of Crystalline Rubrene Films with Enhanced Stability. Phys. Chem. Chem. Phys. 2005, 7, 2850-2853.
(59) Tournebize, A.; Gardette, J.-L.; Taviot-Guého, C.; Bégué, D.; Arnaud, M. A.; Dagron-Lartigau, C.; Medlej, H.; Hiorns, R. C.; Beaupré, S.; Leclerc, M.; et al. Is There a Photostable Conjugated Polymer for Efficient Solar Cells? Polym. Degrad. Stab. 2014.

(60) Silva, H. S.; Tournebize, A.; Bégué, D.; Peisert, H.; Chassé, T.; Gardette, J.-L.; Therias, S.; Rivaton, A.; Hiorns, R. C. A Universal Route to Improving Conjugated Macromolecule Photostability. RSC Adv. 2014, 4, 5491954923.

(61) Risko, C.; McGehee, M. D.; Brédas, J.-L. A QuantumChemical Perspective into Low Optical-Gap Polymers for Highly-Efficient Organic Solar Cells. Chem. Sci. 2011, 2, 1200-1218.

Jackson, N. E.; Savoie, B. M.; Kohlstedt, K. L.; Olvera de la Cruz, M.; Schatz, G. C.; Chen, L. X.; Ratner, M. A. Controlling Conformations of Conjugated Polymers and Small Molecules: The Role of Nonbonding Interactions. J. Am. Chem. Soc. 2013, 135, 10475-10483.

(63) Heumueller, T.; Mateker, W. R.; Sachs-Quintana, I. T.; Vandewal, K.; Bartelt, J. A.; Burke, T. M.; Ameri, T.; Brabec, C. J.; McGehee, M. D. Reducing Burn-in Voltage Loss in Polymer Solar Cells by Increasing the Polymer Crystallinity. Energy Environ. Sci. 2014, 7, 2974-2980.

Cowan, S. R.; Leong, W. L.; Banerji, N.; Dennler, G.; Heeger, A. J. Identifying a Threshold Impurity Level for Organic Solar Cells : Enhanced First-Order Recombination Via Well- Defi Ned PC 84 BM Traps in Organic Bulk Heterojunction Solar Cells. Adv. Funct. Mater. 2011, 21, 3083-3092.

(65) Kaake, L.; Dang, X.-D.; Leong, W. L.; Zhang, Y.; Heeger, A.; Nguyen, T.-Q. Effects of Impurities on Operational Mechanism of Organic Bulk Heterojunction Solar Cells. Adv. Mater. 2013, 25, 1706-1712.

(66) Lewis, J. S.; Weaver, M. S. Thin-Film Permeation-Barrier Technology for Flexible Organic Light-Emitting Devices. IEEE J. Sel. Top. Quantum Electron. 2004, 10, 45-57.

Kondakov, D. Y.; Pawlik, T. D.; Nichols, W. F.; Lenhart, W. C. Free-Radical Pathways in Operational Degradation of OLEDs. J. Soc. Inf. Disp. 2008, 16, 37-46.

(68) Kondakov, D. Y. Role of Chemical Reactions of Arylamine Hole Transport Materials in Operational Degradation of Organic Light-Emitting Diodes. J. Appl. Phys. 2008, 104, 084520 .

(69) Scholz, S.; Walzer, K.; Leo, K. Analysis of Complete Organic Semiconductor Devices by Laser

Desorption/lonization Time-of-Flight Mass Spectrometry. Adv. Funct. Mater. 2008, 18, 2541-2547.

Choi, A. Y.; Yamaguchi, T.; Han, C.-H. A Photochemical Investigation into Operational Degradation of Arylamines in Organic Light-Emitting Diodes. Res. Chem. Intermed. 2012, 39, 1571-1579.

(71) Jarikov, V. V. Improving Operating Lifetime of Organic Light-Emitting Diodes with Polycyclic Aromatic Hydrocarbons as Aggregating Light-Emitting-Layer Additives. J. Appl. Phys. 2006, 100, 014901. 
1

2

3

4

5

6

7

8

9

10

11

12

13

14

15

16

17

18

19

20

21

22

23

24

25

26

27

28

29

30

31

32

33

34

35

36

37

38

39

40

41

42

43

44

45

46

47

48

49

50

51

52

53

54

55

56

57

58

59

60
(72) Jarikov, V. V.; Kondakov, D. Y.; Brown, C. T. Efficient and Extremely Long-Lived Organic Light-Emitting Diodes Based on Dinaphthylperylene. J. Appl. Phys. 2007, 102, 104908.

(73) Schmidbauer, S.; Hohenleutner, A.; König, B. Chemical Degradation in Organic Light-Emitting Devices: Mechanisms and Implications for the Design of New Materials. Adv. Mater. 2013, 25, 2114-2129.
(74) Windt, D. L. IMD-Software for Modeling the Optical Properties of Multilayer Films. Comput. Phys. 1998, 12, 360-370. 


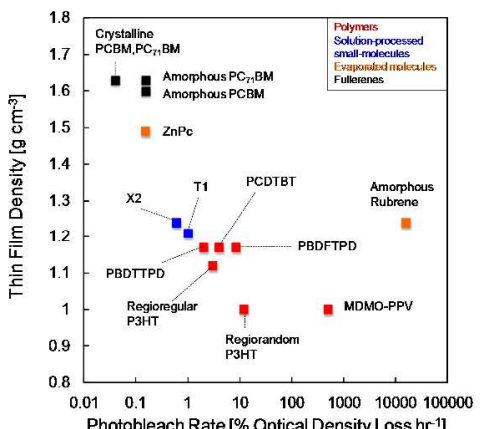

Design rules for improving the chemical stability of organic photovoltaic materials are sought. Aging films of polymers, solution-processed oligomers, and solution-processed and evaporated small molecules in air suggests that stiff, planar molecules and polymers that form a dense, crystalline morphology are desired for increased photo-oxidative stability. 